\title{
Mechanical and metallurgical studies of multi-walled carbon nanotube- reinforced aluminium metal matrix surface composite by friction stir processing
}

\author{
R. Raja*, Sabitha Jannet and S. Rajesh Ruban \\ Assistant Professor, Mechanical Department, Karunya Institute of Technology and Sciences, Coimbatore-641114, \\ Tamil Nadu, India
}

Received: 01-March-2021; Revised: 15-May-2021; Accepted: 17-May-2021

(C2021 R. Raja et al. This is an open access article distributed under the Creative Commons Attribution (CC BY) License, which permits unrestricted use, distribution, and reproduction in any medium, provided the original work is properly cited.

\begin{abstract}
The aluminum alloy 5083 was reinforced with multi-walled carbon nanotubes (MWCNTs) by using friction stirprocessing (FSP). Different MWCNT volume percentages of 0, 6.06, 12.12, and 18.18\% were reinforced into the 5083 aluminium metal matrix. Tensile tests were carried out, and a $24 \%$ increase was achieved with $12.12 \%$ MWCNTs. Hardness was obtained within the stir zone with the 6.06\% of MWCNTs. Scanning Electron Microscopy (SEM) analysis revealed the breakdown of MWCNTs, thus leading to uniform dispersion. Wear rate decreased by $18 \%$ with an increase in MWCNTs.
\end{abstract}

Keywords

Multi-walled carbon nanotubes, SEM, Wear rate, Tensile strength, FSP.

\section{Introduction}

Aluminum alloys play a major role in the aircraft, shipbuilding, and automotive industries because of their superior strength-to-weight ratio. The aluminum alloy 50830 has been used in the shipbuilding industry due to its corrosion resistance properties wants is a nanoparticle that has unique properties based on its structure. Moreover, the presence of carbon results in a very high wear resistance. Its high tensile strength along with its good electrical properties makes it a desirable reinforcement for aluminum alloys. Friction stir processing is a solidstate processing technology that has acquired significant attention in recent years because of the solid-state processing wherein the mixing of materials takes place in the plastic state. This removes the disadvantages of liquid-state processing such as casting, which occurs in high temperatures and leads to various defects, in turn reducing the strength of the composites. These were the motivation behind the current study. In the present study, MWCNTs were reinforced in the magnesium-based aluminum alloy 50830 . This study exploits the presence of carbon as a self-lubricating feature.

*Author for correspondence

643
The following are the objectives of this study:

- To reinforce multiwalled carbon nanotubes in an aluminum matrix by friction stir processing.

- To test the fabricated surface aluminum nanocomposites for various mechanical and wear properties.

- To evaluate the microstructure of the fabricated composite.

\section{Literature review}

Presently, a significant attention is being to the influence of the mixing technique on carbon nanotubes (CNTs). The chemical and thermal stability properties of CNTs and their high yield strength and elastic modulus make them the best option for reinforcement. The AZ31 aluminum alloy reinforced with CNTs exhibited a significant increase in wear compared to the currently available alloys [1]. Addition of $2.0 \mathrm{wt} \%$ of CNTs to the 2024 aluminum alloy led to a considerable grain refinement, but shortening of CNTs occurred during the ball-milling process [2]. Independently reinforced n-A12O3 composites showed a lower wear rate than independently reinforced CNTs; however, its coefficient was higher [3]. In additive metallurgy, dispersion led to a better and uniform dispersion than in ball milling [4]. The maximum tensile strength was achieved with a 75/25 volume ratio of CNTs and cerium oxide [5]. The CNTs 
embedded uniformly in the stir zone and were not affected by the thermomechanical processing due to their multiwall structure [6]. It was observed that aluminum metal matrix nanocomposites are very sensitive to the directional behavior of CNTs, nonstraight shape, and aspect ratio [7]. Damaged carbonaceous products were found in the stir zone due to severe plastic deformation and shear stress [8]. Compact bonding led to uniform dispersion of CNTs in the $\mathrm{Mg}-6 \mathrm{Zn}$ matrix [9]. The distribution of reinforcement particles was uniform in the stir zone of AA6063 and was refined due to the thermomechanical effect of the FSP process [10]. The tangled multiwalled carbon nanotubes (MWCNTs) could not bear the thermomechanical conditions imposed during friction stir processing (FSP) [11]. The flow stress and the Zener-Hollomon parameter improved with a decreasing temperature an and increasing strain rate. The addition of CNTs led to a significant increase in the activation energy of plastic deformation, corroborating the enhanced resistance of the nanocomposite to hot deformation [12] When the RHA reinforcement is more than $50 \%$, hardness values are not affected by the presence of graphite. Residual stresses without reinforcement depend on process parameters such as traverse speed, rotational speed, and tool pin profile. But the hardness was higher in the stir zone of the FSP Al-A12O3 nanocomposite than in alloys without particle materials [13]. Commercially pure aluminum powders (99.9\% with $30 \mathrm{~nm}$ size) and alumina powders were cold-compacted and friction stir-processed [14]. The resulting ultrafine grains significant increased during hardening, thus improving the mechanical performance [15]. AA5052/A12O3 surface composites friction stir-processed with 3 or 4 passes exhibited superior tensile and yield strengths [16]. When A356 was reinforced with $\mathrm{A} 12 \mathrm{O} 3$ using FSP, the surface composite obtained showed a low friction coefficient and wear rates compared to the nonreinforced material [17]. So far, based on the literature, a substantial amount of work has been carried out on FSP of MWCNTs. But FSP on Aluminum Alloy 5083 o is yet to be explored. In this work, a detailed analys is of the effects of MWCNTs has been carried out and reported.

\section{Materials and methods}

Aluminum alloy 5083 with magnesium and traces of manganese and chromium were identified for this study due to its high corrosion properties and most upper strength in the category of non-heat-treatable alloys. MWCNTS were used due to their high strength, as pect ratio, and modulus. The specifications of the MWCNTs used and the chemical composition of the A15083 aluminum alloy are shown in Table 1 and Table 2, respectively.

The schematic of our work is shown in Figure 1. A groove was cut and compacted with MWCNT particles. FSP was carried out using a tool. The dimensions of the tool are shown in Figure 2. The process parameters identified were a force of $20 \mathrm{KN}$, a feed of $30 \mathrm{~mm} / \mathrm{min}$, and an rpm of 1300 . Four specimens of dimensions $130 \times 75 \times 8$ were used and grooves of $0.4,0.8$, and 1.2 were made by the wire-cut EDM method. These grooves were filled with 6.06, 12.02, and 18.08 vol\% vol of nanoparticles, respectively. The composition is used based on groove depth and dimensions of the workpiece.

The geometry of the FSP tool is mainly related to the dimension of the base material as well as its material flow characteristics. The specimens were machined to a dimension of $6 \mathrm{~mm} \times 6 \mathrm{~mm} \times 30 \mathrm{~mm}$. Height loss was monitored using a computer-aided data acquisition system. The friction stir-processed plates are as shown in Figure 3. The surface of the specimen was slid on a hardened chromium steel disc. The parameters used for the test are a sliding velocity of $1.5 \mathrm{~m} / \mathrm{s}$, a normal force of $25 \mathrm{~N}$, and a sliding distance of $2500 \mathrm{~m}$.

Table 1 Chemical composition of A15083 alloy

\begin{tabular}{llllllllll}
\hline Elements & $\mathbf{S i}$ & $\mathbf{F e}$ & $\mathbf{C u}$ & $\mathbf{M n}$ & $\mathbf{M g}$ & $\mathbf{Z n}$ & $\mathbf{T i}$ & $\mathbf{C r}$ & $\mathbf{A l}$ \\
\hline $\begin{array}{l}\text { Percentagec } \\
\text { omposition }\end{array}$ & 0.4 & 0.4 & 0.1 & $0.4-0.1$ & $4-4.9$ & 0.25 & 0.15 & $.05-0.25$ & Bal \\
\hline
\end{tabular}

Table 2 Specifications of MWCNT TYPE 5

\begin{tabular}{ll}
\hline Appearance & Black \\
\hline Appearance (form) & Powder \\
\hline Assay & Min 95\% \\
\hline Length & $10-30 \mu \mathrm{m}$ \\
\hline OD & $30-50 \mathrm{~nm}$ \\
\hline
\end{tabular}




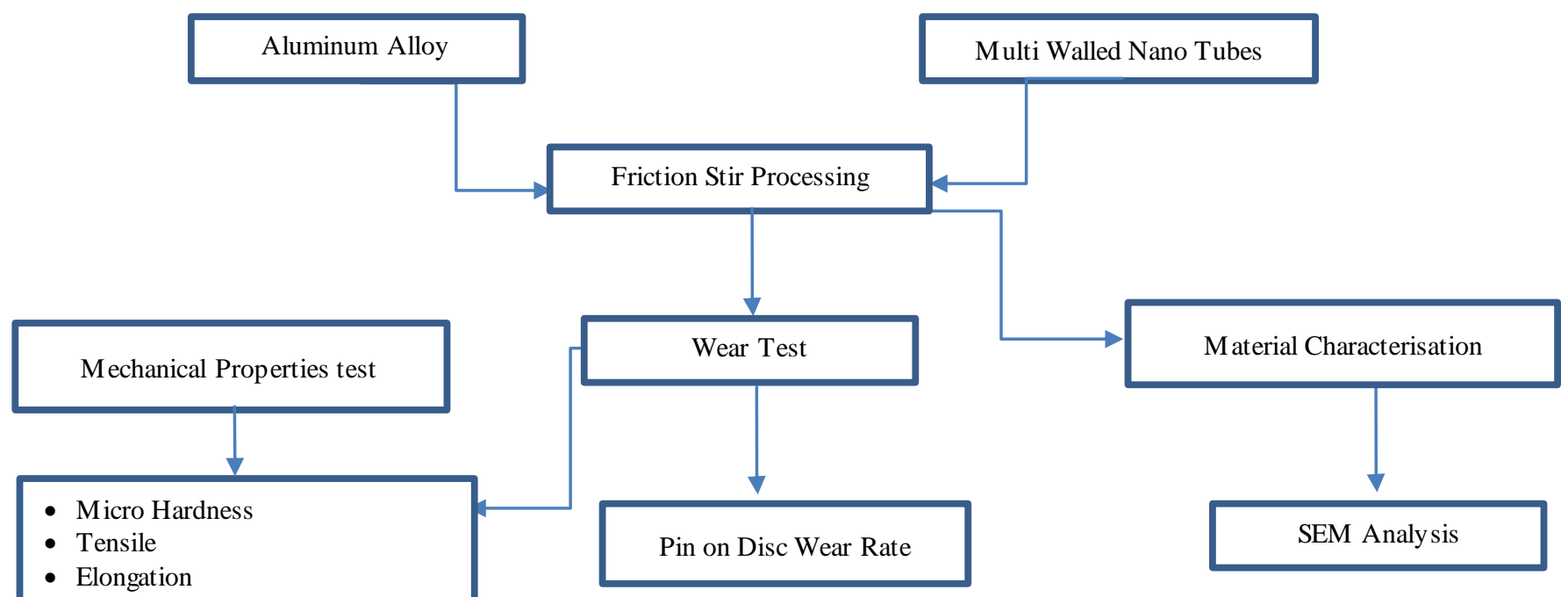

Figure 1 Schematic flow of work done

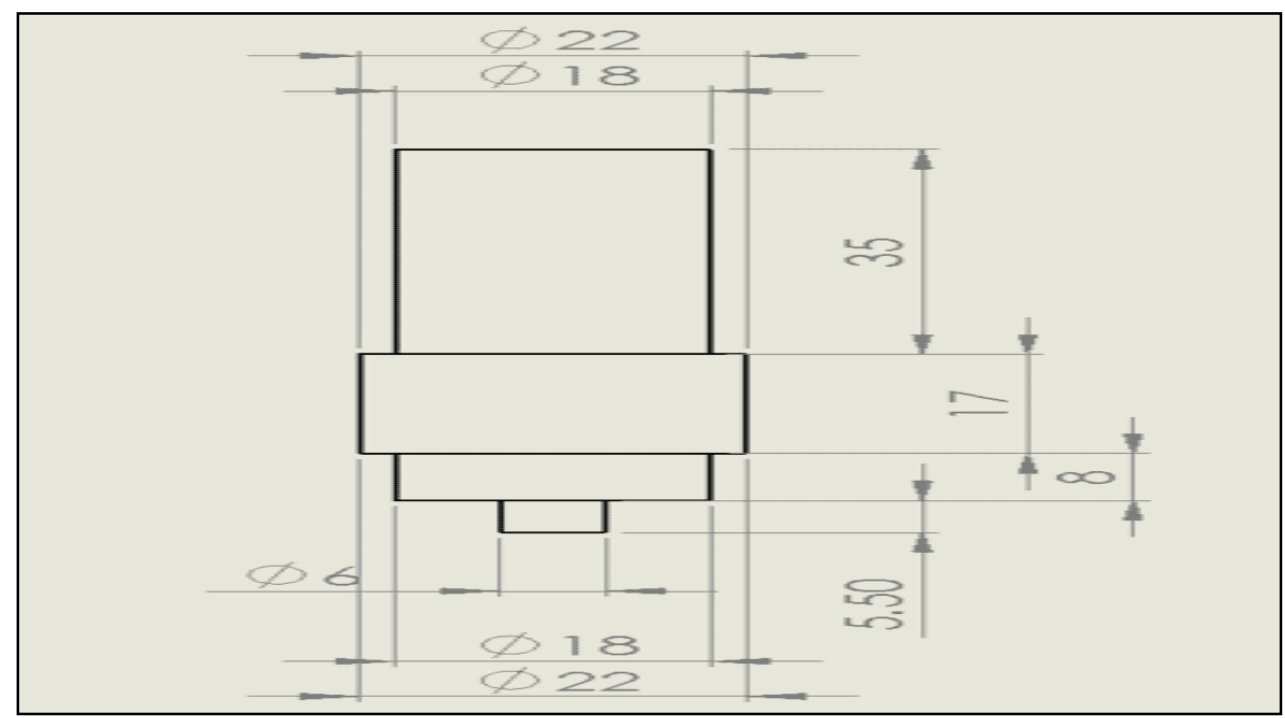

Figure 2 Tool dimensions used for the FSP process

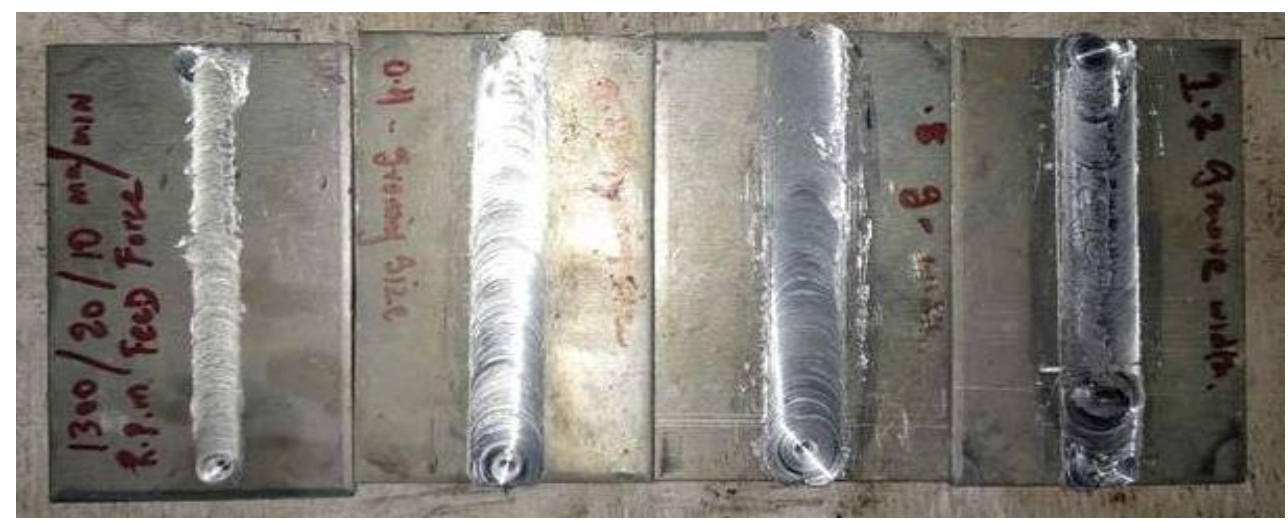

Figure 3 Crown appearance of the FSPed sample

645 


\section{Results and discussion}

\subsection{Tensile behaviour}

Figure 4 shows an increase in the ultimate tensile strength (MPa), which might be due to the Orowan looping mechanism, leading to the formation of back stress and an increase in dislocation density. This forms a barrier for further movement of dislocations and increased lattice strain. Shear lag is due to the load transfer from the matrix to the CNTs. The strain misfit between the elastic reinforcement and the plastic matrix might also contribute to the increased tensile strength [18, 19]. Orowan strengthening may be the mechanism behind the increase in strength. This strengthening is primarily due to the interaction between the lattice dislocations and CNTs. The critical interparticle distance is achieved by fragmentation of the CNTs [20]. The stirring action of the pin might be the reason for the uniform distribution of the CNTs, resulting in superior mechanical properties [21]. MWCNTs are present as nucleation sites for void formation at a reinforcement percentage of more than $5 \%$. This nucleation might start recrystallization at an appropriate high temperature [22]. Formation of A14C3 may not be possible since the operating temperature for this process is only around $8000^{\circ} \mathrm{C}$ and a higher operating temperature is needed. This could also have increased the tensile strength since it is reported that the formation of $\mathrm{A} 14 \mathrm{C} 3$ in the aluminum/CNT interface would increase the loadbearing capacity of the composite [23]. The mechanisms mentioned above may be further validated by the composite strength model. The higher the aspect ratio, the higher the strength of the composite, thus having a notable effect on strength [24]. However, the effect of aspect ratio for randomly distributed MWCNTs is just half the actual aspect ratio [25]. The refined microstructure due to FSP leads to severe plastic deformation and a hindrance to crack growth is established, thus increasing elongation [26]. The dispersion of MWCNTs is better in 6 and 12 percentage, thus strengthening the composite. This might be due to the reinforcement filling the voids present in the matrix. But a further increase in MWCNTs results in deterioration of the strength, which might be due to the reduction in the densification process and thus the decrease in the density of the composites. The critical length of the MWCNTs also plays a major role in the strength of the composite fabricated. The critical length equation validates this for fiber reinforcements can be applied for MWCNTs also for load transfer strengthening mechanism. The significant length is given by Equation 1 [27]:

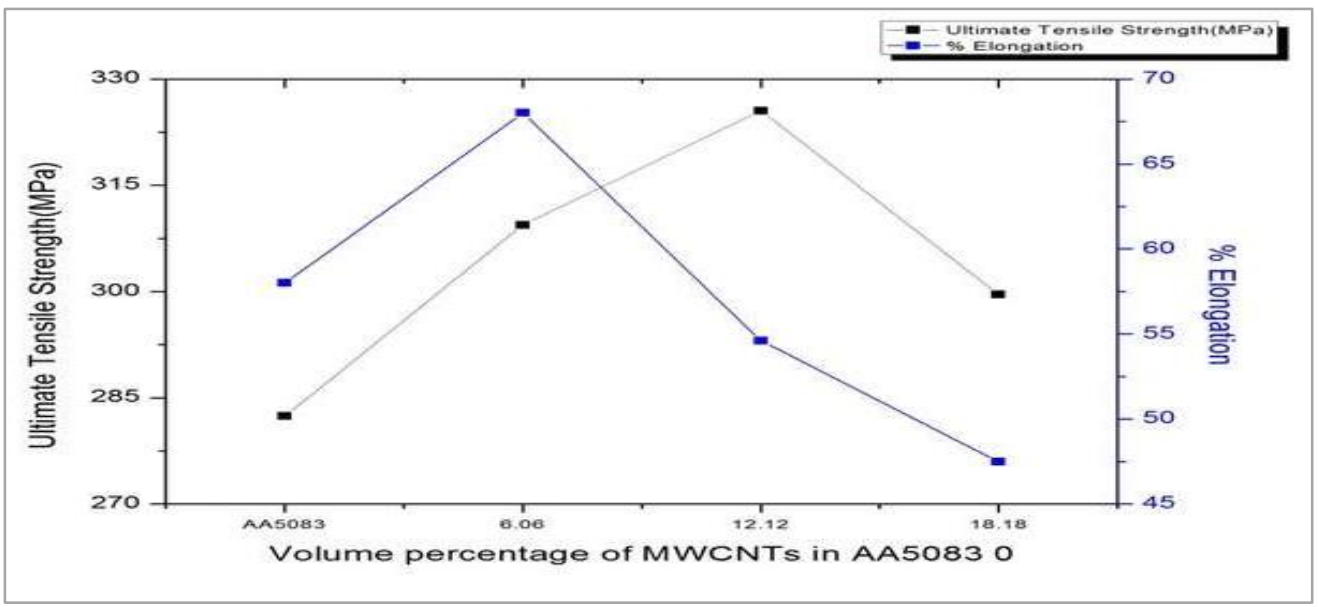

Figure 4 The effect weight percentage of MWCNTs on the UTS and elongation

$l_{c}=\frac{\sigma_{t . c n t} D_{c n t}}{2_{\tau m}}$

where the multiple mechanism theory is given by Equation 2:

$\sigma_{c}=\sigma_{m}+\Delta \sigma_{L . T}+\Delta \sigma_{L . M}+\Delta \sigma_{O R O W A N}$

where $\sigma_{c}$ is the strength of the composite, $\sigma_{m}$ is the strength of the matrix, $\Delta \sigma_{L . T}$ is the improved strength due to load transfer, $\Delta \sigma_{L . M}$ is the improved strength due to thermal mismatch and $\Delta \sigma_{\text {OROWAN }}$ is the improved strength due to Orowan looping. The above theory is based on the dislocation theory and thus plastic deformation should be considered [28].

4.2SEM (Scanning electron microscopy) analysis From Figure 5, it may be observed that the CNTs are deformed and fractured to form a homogenous distribution. This might be due to the severe plastic deformation and shear strain developed in a short 
duration. Grain refinement transformed from being discontinuous to continuous dynamic recrystallization due to the hard inclusions. The CNTs were sheared due to the load applied through the tool pin during FSP. There is a reduction in grain size from the average size. The MWCNTs in the grain boundaries of the aluminum matrix impeded grain growth and further resulted in enhanced mechanical properties due to the microstructure. Notable bonding was observed between the matrix and CNTs. Since aluminum has 12 slip systems, grain refinement can be conveniently obtained by plastic deformation and thus an increase in hardness $[29,30]$.

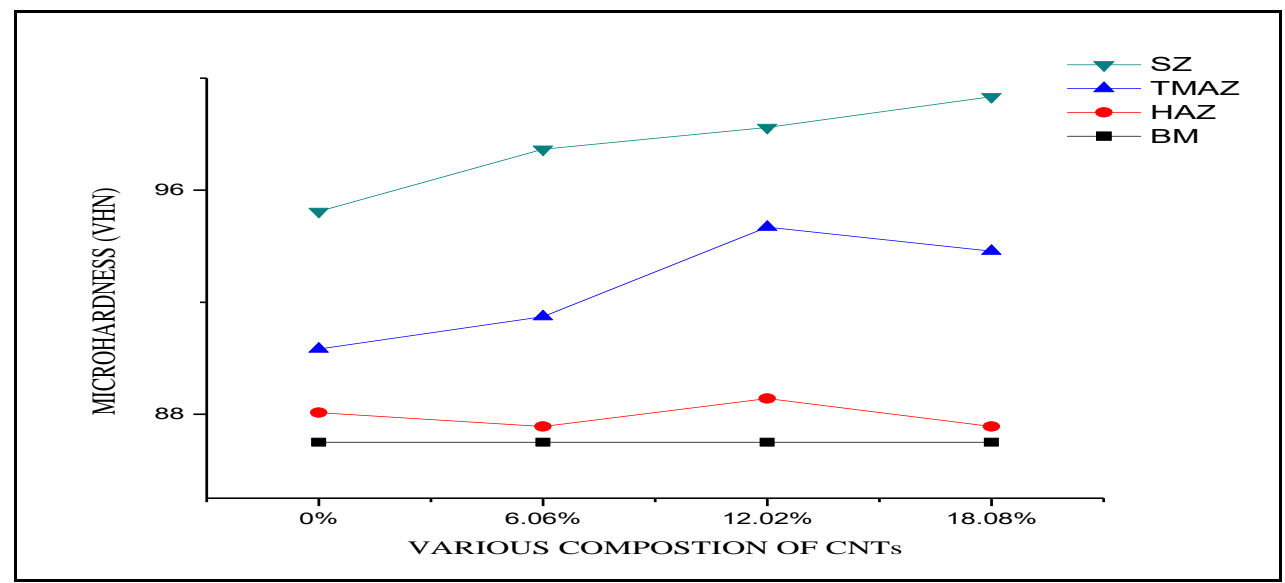

Figure 5 The effect weight percentage of MWCNTs on the MicroHardness

\section{Microhardness test}

The increase in hardness in the stir zone might be attributed to either of these mechanisms: (i) Orowan strengthening, also known as dislocation bowing around particles, and (ii) grain size refinement. In the former, the dislocations form a loop around the particle, called the Orowan loop [31]. Grain or substructure strengthening is shown in Figure 6. Grain size refinement can increase hardness based on the Hall-Petch equation. The coefficient of thermal expansion, being different for both the matrix and the reinforcement, also contributed to the hardness upshot [32]. The nanosize of the reinforcement particle leads to the pinning of dis locations, leading to the reduction in grain growth. This pinning effect stops the dislocations fromfurther sliding due to grain boundary [33]. Also, the hindrance of the movement of dislocations can be attributed to the presence of MWCNTs due to which elastic modulus mismatch and thermal expansion mismatch occur between the MWCNTs and the aluminum matrix. At 5\% and more of MWCNTs, the strain hardening effect can also be attributed to the increase in strength compared to the base metal [34]. In nano-sized reinforcements, the dislocation density evolved by athermal storage of dislocations due to dislocation pinning and annihilation of these dislocations due to dynamic recovery [35]. This might lead to plastic deformation from conventional dislocation slip to grain boundary migration. Strengthening due to carbon atoms is not possible since the solubility of carbon atoms in aluminum atoms is very low at low temperatures [36]. Higher restriction to localized matrix deformation can also be attributed to an increase in hardness [37].

\section{Wear behaviour}

The inclusion of MWCNTs reduces wear loss as they hinder the crack propagation. Also, MWCNTs can remain between the two contacting surfaces and diminish the direct contact effect. Furthermore, the frictional temperature developed can be reduced by the presence of MWCNTs. Thus at optimum concentration, MWCNTs can provide good tribological properties (Figure 7).

Moreover, the aspect ratio, orientation, and interaction with the matrix contribute to an improvement in these properties [38]. Formation of a graphene layer might be one of the factors that decrease in wear rate since there will be an increase in layers formed with an increase in the quantity of MWCNTs reinforced in the matrix [39]. Oxidation between the matrix and MWCNTs is inhibited and does not occur. The existence of the peeling surface of the MWCNTs on the surface of the composite also contributes to the reduction in wear 12.02 percentage by avoiding plowing [40]. Also, the increase in hardness decreases wear rate. A great reduction in direct contact between the nanocomposite surface and the disc also reduces wear rate. The primary mechanism is the load-bearing 
ability of the MWCNTs in the aluminum matrixreinforced interface [41]. The MWCNTs mainly improve the strength and hardness of the matrix, and thus better resistance to plastic deformation is achieved, leading to the reduction in the plowing effect of the reinforcement from the matrix. This can also be attributed to a decrease in weight loss with an increase in MWCNTs [42, 43].

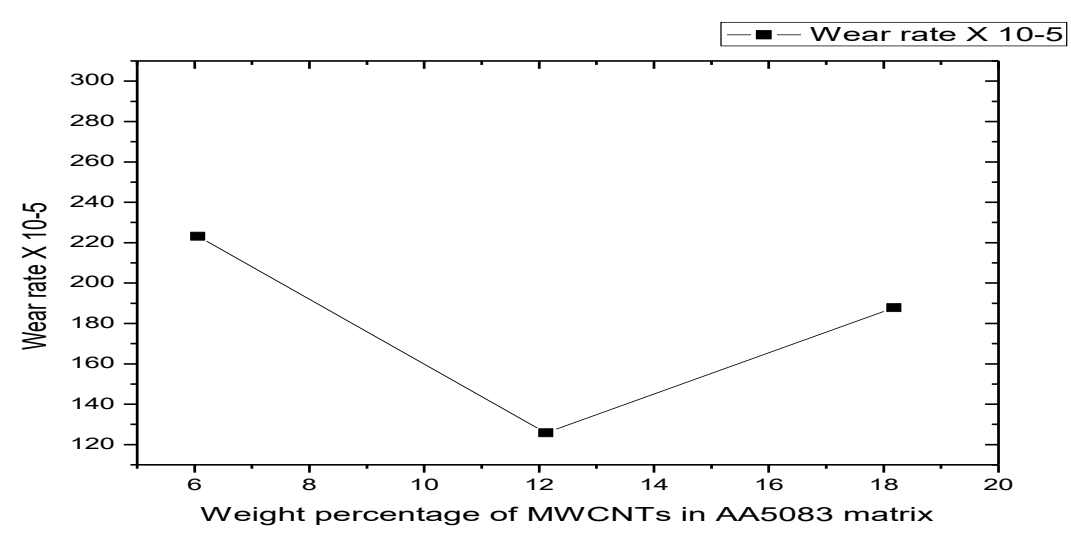

Figure 6 Effect of weight percentage of MWCNT on the wear rate

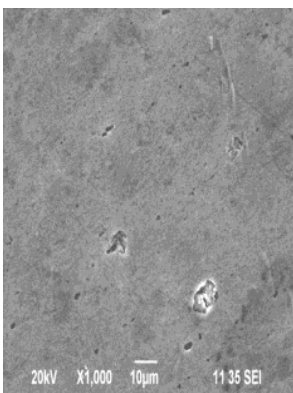

(A)

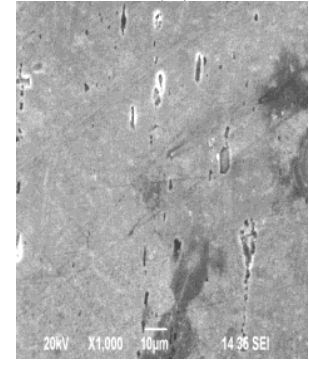

(C)

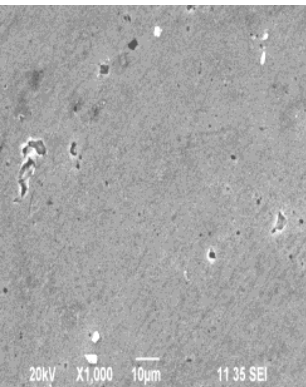

(B)

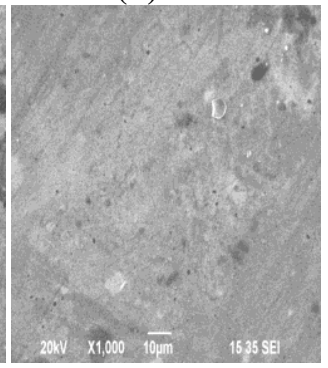

(D)
Figure 7 SEM Results for (a) FSP of (b) A15083 with $6 \%$ vol CNT (c) Al5083 with $12 \%$ vol CNT (d) A15083 with $18 \%$ vol CNT

\subsection{Limitations}

FSP could produce acceptable results in the current study. But there were a few limitations to the severe plastic deformation due to the process. This could be overcome by employing a pre-heating system or a post-heating system to avoid generation of stress.

\section{Conclusion and future work}

The tensile strength followed a downward trend with the increase in the volume percentage of reinforcement. This clearly shows that the new composites formed exhibited a lower tensile strength when compared to AA 5083 under FSP. The distribution of reinforcements, microstructure, and bonding has been observed using SEM photographs. The wear rate decreases with the inclusion of MWCNTs but an increase in MWCNT concentration from $12.02 \%$ to $18.08 \%$ leads to a surge in the wear rate. Wear Rate is closely as sociated with the hardnes s of the composite: the harder the surface, the less the wear rate. The microhardness value graph clearly shows an increase in hardness when MWCNTs are added.

Wear mechanisms and fracture mechanisms could be further studied by employing a new methodology to avoid the damage to the structure of the MWCNTs.

\section{Acknowledgment}

None.

\section{Conflicts of interest}

The authors have no conflicts of interest to declare.

\section{References}

[1] Lim DK, Shibayanagi T, Gerlich AP. Synthesis of multi-walled CNT reinforced aluminium alloy composite via friction stir processing. Materials Science and Engineering: A. 2009; 507(1-2):194-9. 
[2] Jamshidijam M, Akbari-Fakhrabadi A, Masoudpanah SM, Hasani GH, Mangalaraja RV. Wear behavior of multiwalled carbon nanotube/AZ31 composite obtained by friction stir processing. Tribology Transactions. 2013; 56(5):827-32.

[3] Mokdad F, Chen DL, Liu ZY, Xiao BL, Ni DR, MaZY. Deformation and strengthening mechanisms of a carbon nanotube reinforced aluminum composite. Carbon. 2016; 104:64-77.

[4] Lu D, Jiang Y, Zhou R. Wear performance of nanoA12O3 particles and CNTs reinforced magnesium matrix composites by friction stir processing. Wear. 2013; 305(1-2):286-90.

[5] Chen M, Fan G, Tan Z, Xiong D, Guo Q, Su Y, et al. Design of an efficient flake powder metallurgy route to fabricate CNT/6061Al composites. Materials \& Design. 2018; 142:288-96.

[6] Hosseini SA, Ranjbar K, Dehmolaei R, Amirani AR. Fabrication of Al5083 surface composites reinforced by CNTs and cerium oxide nano particles via friction stir processing. Journal of Alloys and Compounds. 2015; 622:725-33.

[7] Hassanzadeh-aghdam MK, Ansari R, Mahmoodi MJ. Thermal expanding behavior of carbon nanotubereinforced metal matrix nanocomposites-a micromechanical modeling. Journal of Alloys and Compounds. 2018; 744:637-50.

[8] Maurya R, Kumar B, Ariharan S, Ramkumar J, Balani $\mathrm{K}$. Effect of carbonaceous reinforcements on the mechanical and tribological properties of friction stir processed Al6061 alloy. Materials \& Design. 2016; 98:155-66.

[9] Huang Y, Li J, Wan L, Meng X, Xie Y. Strengthening and toughening mechanisms of CNTs/Mg-6Zn composites via friction stir processing. Materials Science and Engineering: A. 2018; 732:205-11.

[10] Abraham SJ, Madane SC, Dinaharan I, Baruch LJ. Development of quartz particulate reinforced AA6063 aluminum matrix composites via friction stir processing. Journal of Asian Ceramic Societies. 2016; 4(4):381-9.

[11] Khodabakhshi F, Gerlich AP, Švec P. Reactive frictionstir processing of an Al-Mg alloy with introducing multi-walled carbon nano-tubes (MW-CNTs): microstructural characteristics and mechanical properties. Materials Characterization. 2017; 131:35973

[12] Mokdad F, Chen DL, Liu ZY, Ni DR, Xiao BL, MaZY. Hot deformation and activation energy of a CNTreinforced aluminum matrix nanocomposite. Materials Science and Engineering: A. 2017; 695:322-31.

[13] Alaneme KK, Sanusi KO. Microstructural characteristics, mechanical and wear behaviour of aluminium matrix hybrid composites reinforced with alumina, rice husk ash and graphite. Engineering Science and Technology, an International Journal. 2015; 18(3):416-22.

[14] Xu H, Hubbard CR, An K, Feng Z, Wang XL, Qu J. Neutron diffraction measurement of residual stresses in friction stir processed nanocomposite surface layer. Advanced Engineering Materials. 2009; 11(8):650-3.

[15] Hu CM, Lai CM, Du XH, Ho NJ, Huang JC. Enhanced tensile plasticity in ultrafine-grained metallic composite fabricated by friction stir process. Scripta Materialia. 2008; 59(11):1163-6.

[16] Sharifitabar M, Sarani A, Khorshahian S, Afarani MS. Fabrication of 5052Al/A12O3 nanoceramic particle reinforced composite via friction stir processing route. Materials \& Design. 2011; 32(8-9):4164-72.

[17] Mazaheri Y, Karimzadeh FA, Enayati MH. Tribological behavior of A356/Al 2 O 3 surface nanocomposite prepared by friction stir processing. Metallurgical and Materials Transactions A. 2014; 45:2250-9.

[18] Yuan Q, Zeng X, Wang Y, Luo L, Ding Y, Li D, et al. Microstructure and mechanical properties of Mg- $4.0 \mathrm{Zn}$ alloy reinforced by $\mathrm{NiO}$-coated CNTs. Journal of Materials Science \& Technology. 2017; 33(5):452-60.

[19] Sahraeinejad S, Izadi H, Haghshenas M, Gerlich AP. Fabrication of metal matrix composites by friction stir processing with different particles and processing parameters. Materials Science and Engineering: A. 2015; 626:505-13.

[20] Kim WJ, Yu YJ. The effect of the addition of multiwalled carbon nanotubes on the uniform distribution of $\mathrm{TiC}$ nanoparticles in aluminum nanocomposites. Scripta Materialia. 2014; 72:25-8.

[21] Bakshi SR, Agarwal A. An analysis of the factors affecting strengthening in carbon nanotube reinforced aluminum composites. Carbon. 2011; 49(2):533-44.

[22] Majid M, Majzoobi GH, Noozad GA, Reihani A, Mortazavi SZ, Gorji MS. Fabrication and mechanical properties of MWCNTs-reinforced aluminum composites by hot extrusion. Rare Metals. 2012; 31:372-8.

[23] Singla D, Amulya K, Murtaza Q. CNT reinforced aluminium matrix composite-a review. Materials Today: Proceedings. 2015; 2(4-5):2886-95.

[24] Tiong SC. Recent progress in the development and properties of novel metal matrix nanocomposites reinforced with carbon nanotubes and graphene nanosheets. Materials Science and Engineering: R: Reports. 2013; 74(10):281-350.

[25] Liu ZY, Xiao BL, Wang WG, Ma ZY. Developing high-performance aluminum matrix composites with directionally aligned carbon nanotubes by combining friction stir processing and subsequent rolling. Carbon. 2013; 62:35-42.

[26] Liu ZY, Xiao BL, Wang WG, Ma ZY. Singly dispersed carbon nanotube/aluminum composites fabricated by powder metallurgy combined with friction stir processing. Carbon. 2012; 50(5):1843-52.

[27] Xie S, Li W, Pan Z, Chang B, Sun L. Mechanical and physical properties on carbon nanotube. Journal of Phy sics and Chemistry of Solids. 2000; 61(7):1153-8.

[28] Park JG, Keum DH, Lee YH. Strengthening mechanisms in carbon nanotube-reinforced aluminum composites. Carbon. 2015; 95:690-8. 
[29] Yoo SJ, Han SH, Kim WJ. Strength and strain hardening of aluminum matrix composites with randomly dispersed nanometer-length fragmented carbon nanotubes. Scripta Materialia. 2013; 68(9):7114.

[30] Hamdollahzadeh A, Bahrami M, Nikoo MF, Yusefi A, Givi MB, Parvin N. Microstructure evolutions and mechanical properties of nano-sic-fortified aa7075 friction stir weldment: the role of second pass processing. Journal of Manufacturing Processes. 2015; 20:367-73.

[31] Dong S, Zhou J, Hui D, Wang Y, Zhang S. Size dependent strengthening mechanisms in carbon nanotube reinforced metal matrix composites. Composites Part A: Applied Science and Manufacturing. 2015; 68:356-64.

[32] Oden LA, McCune RA. Phase equilibria in the Al-Si-C system. Metallurgical Transactions A. 1987; 18:200514.

[33] Goh CS, Wei J, Lee LC, Gupta M. Development of novel carbon nanotube reinforced magnesium nanocomposites using the powder metallurgy technique. Nanotechnology. 2005; 17(1).

[34] Sudhakar M, Rao CS, Saheb KM. Production of surface composites by friction stir processing-a review. Materials Today: Proceedings. 2018; 5(1):929-35.

[35] Xu W, Ke L, Xing L, Zhao X. On the influence of carbon nanotubes on the wear performance and hardness of aluminium matrix composites. Materialwissenschaft und Werkstofftechnik. 2011; 42(5):375-8.

[36] Zhou M, Qu X, Ren L, Fan L, Zhang Y, Guo Y, et al. The effects of carbon nanotubes on the mechanical and wear properties of AZ31 alloy. Materials. 2017; 10(12):1-17.

[37] Zhang XR, Pei XQ, Wang QH, Wang TM, Chen SB. The friction and wear properties of carbon nanotubes/graphite/carbon fabric reinforced phenolic polymer composites. Advanced Composite Materials. 2015; 24(sup 1):147-59.

[38] Kumar H, Prasad R, Kumar P, Tewari SP, Singh JK. Mechanical and tribological characterization of industrial wastes reinforced aluminum alloy composites fabricated via friction stir processing. Journal of Alloys and Compounds. 2020.

[39] Patel V, Li W, Liu X, Wen Q, Su Y, Shen J, et al. Tailoring grain refinement through thickness in magnesium alloy via stationary shoulder friction stir processing and copper backing plate. Materials Science and Engineering: A. 2020.

[40] Moharrami A, Razaghian A, Paidar M, Šlapáková M, Ojo OO, Taghiabadi R. Enhancing the mechanical and tribological properties of $\mathrm{Mg} 2 \mathrm{Si}$-rich aluminum alloys by multi-pass friction stir processing. Materials Chemistry and Physics. 2020.

[41] Mazaheri Y, Jalilvand MM, Heidarpour A, Jahani AR. Tribological behavior of $\mathrm{AZ} 31 / \mathrm{ZrO} 2$ surface nanocomposites developed by friction stir processing. Tribology International. 2020.
[42] Satyanarayana MV, Kumar A. Influence of cooling media in achieving grain refinement of AA2014 alloy using friction stir processing. Proceedings of the Institution of Mechanical Engineers, Part C: Journal of Mechanical Engineering Science. 2020; 234(22):452034.

[43] Mabuwa S, Msomi V. The effect of friction stir processing on the friction stir welded AA $1050-\mathrm{H} 14$ and AA6082-T6 joints. Materials Today: Proceedings. 2020; 26:193-9.

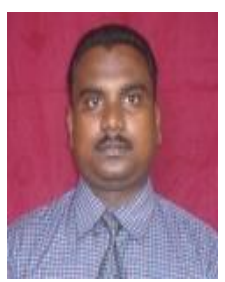

Dr. R. Raja has completed his Ph.D degree from Anna University in the year 2015. He has completed his M.E and B.E from Bharathiar University in the year 1999 and 1996 respectively. He has 20 years of teaching experience. He has been serving in Karunya Institute of Technology \& Sciences (Deemed-to-beuniversity) Coimbatore from the year 2000. He has guided 10 M.Tech projects and 30 B.Tech Projects and now guiding 4 Ph.D scholars. He has published 26 papers in the reputed international journals and international conferences. His research interest is Synthesis, Characterization and Machining of Poly mer Matrix Composites and Metal Matrix Composites. He is a life member in ISTE (Indian Society for Technical Education), ISAMPE (Indian Society for Advanced Material Processing Engineering), IRED (Institute of Research Engineers and Doctors) and IAENG (International Association of Engineers).

Email: raja_r11773@karunya.edu

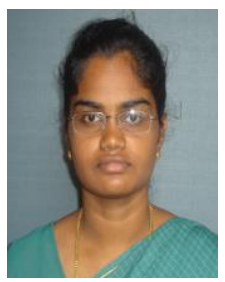

Dr. Sabitha Jannet received her doctoral degree from Anna University Chennai, India. She is presently working as Assistant Professor(S.G) in Department of Mechanical Engineering. Karunya Institute of Technology and Sciences. Her research interest Includes Metal Matrix Composite, Stir Casting and Wear Behaviour. She has published 20 technical articles in peer-reviewed international journals.

Email: sabithajannet@gmail.com

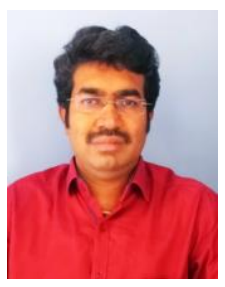

Dr. S. Rajesh Ruban received his doctoral degree from Karunya Institute of Technology and Sciences, Coimbatore, India. $\mathrm{He}$ is presently working as Assistant Professor in Department of Mechanical Engineering. Karuny a Institute of Technology and Sciences. His research interest includes Metal Matrix Composite, Stir Casting and Wear. He has published 20 technical articles in peer-reviewed international journals.

Email: rajeshruban@karuny a.edu 